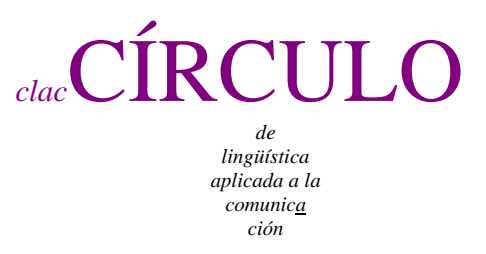

$62 / 2015$

\title{
LOS VERBOS DE OPINIÓN ENTRE LOS VERBOS PARENTÉTICOS \\ Y LOS VERBOS DE RECCIÓN DÉBIL: ASPECTOS SINTÁCTICOS Y SEMÁNTICO-PRAGMÁTICOS
}

\author{
Ramón González Ruiz \\ Universidad de Navarra \\ rgonzalez en unav es
}

\section{Resumen}

El objetivo general de este artículo es ahondar un poco más en algunas de las ideas presentadas en un trabajo previo (González Ruiz 2014) en torno a la gramática, la semántica y las funciones pragmadiscursivas de verbos de opinión como opinar, creer, pensar, imaginar y suponer cuando son empleados en su forma performativa (opino, creo, pienso, imagino, supongo). En particular, con la finalidad de plantear vías de estudio futuras, se persigue reflexionar sobre estas dos cuestiones: a) el grado de la filiación de estos verbos con las propiedades sintácticas y semánticas de los “verbos rectores débiles” según la propuesta de Blanche-Benveniste y Willems (2007 y 2010); b) las diferencias en el semantismo de estos verbos en relación con la modalidad epistémica y la evidencialidad.

Palabras clave: verbos de opinión, verbos débiles, modalidad epistémica, evidencialidad.

González Ruiz, Ramón 2015.

Los verbos de opinión entre los verbos parentéticos y los verbos de rección débil: aspectos sintácticos y semántico-pragmáticos Círculo de Lingüística Aplicada a la Comunicación 62, 148-173. http://www.ucm.es/info/circulo/no62/gonzalezR.pdf http://revistas.ucm.es/index.php/CLAC http://dx.doi.org/10.5209/rev_CLAC.2015.v62.49502

(C) 2015 Ramón González Ruiz

CÍRCULO de Lingüística Aplicada a la Comunicación (clac)

Universidad Complutense de Madrid. ISSN 1576-4737. http://www.ucm.es/info/circulo 


\begin{abstract}
Opinion verbs in Spanish between parenthetical and weak-valency verbs: syntactic and semantic-pragmatic aspects. The aim of this paper is to deepen some of the ideas presented in a previous article (González Ruiz 2014) about the syntax, semantics and pragmatics of Spanish opinion verbs such as opinar, creer, imaginar and suponer when they are used in their performative form (opino, creo, pienso, imagino, supongo). More specifically, in order to suggest new areas for future research, two main points will be discussed: a) the relation between these verbs and the syntactic and semantic properties of the "weak valency verbs", according to the proposal of Blanche-Benveniste and Willems (2007 and 2010); b) the differences in the semantics of these verbs regarding epistemic modality and evidentiality.
\end{abstract}

Key words: Opinion verbs, weak verbs, epistemic modality, evidentiality.

Índice

Resumen 148

Abstract 149

1. La clase de los verbos de opinión 150

2. Los verbos de opinión entre los verbos “débiles”: contornos sintácticos y semánticopragmáticos 152

2.1. Verbos de opinión y subjetividad del lenguaje 152

2.2. Verbos de opinión, verbos parentéticos y verbos de “rección débil”: apuntes de sintaxis discursiva 154

3. Modalidad epistémica y evidencialidad en los verbos de opinión 163

3.1. Verbos de opinión y modalidad epistémica 163

3.2. Verbos de opinión y evidencialidad 166

4. Final 169

Bibliografía 169 
1. La clase de los verbos de opinión

1.1. En las líneas que siguen pretendo ahondar en algunas de las reflexiones presentadas en González Ruiz (2014) en torno a la sintaxis, semántica y funciones pragmadiscursivas de verbos como opinar, creer, pensar, imaginar y suponer cuando son empleados en su forma performativa (opino, creo, pienso, imagino, supongo), especialmente en aquellas referentes a la sintaxis discursiva ${ }^{1}$. Estos verbos pertenecen a una subclase de predicados no factivos de referencia mental, cuyo paradigma ha sido etiquetado con diversas denominaciones: “predicados doxásticos” (Haverkate 1994), “verbos de opinión” (Comesaña 2004), “predicados asertivos débiles” (Hooper 1975), etc. $^{2}$ Las disensiones respecto del significado de estos verbos $\mathrm{y}$, por tanto, del establecimiento de sus límites de extensión, obedecen, entre otras razones, a cuestiones de metalenguaje, empezando por el propio término opinión. Si nos ceñimos al español, son los verbos creer, pensar y opinar, a los cabría añadir otros como parecer $^{3}$, los más característicos de esta clase semántica. A estos se suman otros cuya semántica vinculada a la opinión queda transparentemente reflejada en alguna(s) de las acepciones que proporcionan las definiciones lexicográficas (considerar, entender, estimar); y, por otra parte, también se habla de 'opinión', especialmente cuando son empleados en la primera persona del singular del presente de indicativo, a propósito de otros verbos, la mayor parte de ellos integrables entre los verbos “creadores de mundos”, como presumir, sospechar, suponer, imaginar o figurar(se $)^{4}$. Así pues, en principio, de acuerdo con esta

\footnotetext{
${ }^{1}$ Este trabajo se inscribe en los Proyectos de Investigación El discurso público: estrategias persuasivas y de interpretación, desarrollado por el grupo GRADUN (Grupo Análisis del Discurso. Universidad de Navarra del ICS-Instituto Cultura y Sociedad) de la Universidad de Navarra, y Metadiscurso y lenguaje evaluativo: perspectivas teóricas y de análisis en el discurso periodístico, financiado por el Ministerio de Economía y Competitividad (ref. FFI2012-36309).

${ }^{2}$ En adelanteme referiré a estos verbos como VOP o verbos de opinión, si bien utilizaré otras denominaciones por motivos de variatio.

${ }^{3}$ El DRAE (s.v. parecer) en su segunda acepción dice: “2. intr. Opinar, creer. U. m. c. impers.”.

${ }^{4}$ Un indicio de la vinculación semántica entre estos verbos es la frecuencia de definiciones sinonímicas. La segunda acepción de imaginar en el DRAE es: “2. tr. Presumir, sospechar. U. t. c. prnl.”. En el DUE la tercera acepción de pensar se define así: “Creer u opinar cierto cosa”. Por fin, en el DRAE (s.v. temer): “3. tr. Sospechar, creer”.
} 
aproximación, en los enunciados de (1) y (2) se observa que un mismo contenido proposicional se presenta como una opinión:

(1) Creo/Pienso/Opino/Me parece/Considero/Estimo que ha errado.

(2) Supongo/Presumo/Sospecho/(Me) imagino/Me figuro/(Me) temoque ha errado.

1.2. Los ejemplos (1) y (2) nos sirven para añadir algún dato más. Se ha señalado que el paradigma de verbos cognitivos de opinión también presenta cohesión por algunas características sintácticas. Por ejemplo, Comesaña (2002) sostiene que el esquema sintáctico más frecuente y, por tanto, prototípico es el que se posee dos argumentos (experimentador y objeto experimentado), este último con estructura de cláusula: SUJETO-VB-CDIRECTO clausal. Según esta autora, es con esta estructura sintáctica “con la que los verbos llegan a ser equivalentes o sinónimos, ya que se presenta una relación paradigmática con el sentido de 'mantener una opinión'” (Comesaña 2002: 247). Esta última afirmación puede aceptarse como de trazo grueso, pues, en primer lugar, una lengua como el español dispone de un generoso número de verbos cognitivos -no solo los doxásticos- que se caracteriza por seleccionar prototípicamente una subordinada de objeto directo y que, además, no requieren, desde su propia selección argumental, un objeto indirecto (Delbecque y Lamirov 1999: 1997 y ss.); y, sobre todo, en segundo lugar, cabría preguntarse en qué sentido o hasta qué punto es posible la intercambiabilidad como “equivalentes o sinónimos” entre todos estos verbos cognitivos.

En lo que sigue, algunas reflexiones afectarán a la clase de los VOP como grupo, pero principalmente lo que perseguimos es plantear algunas diferencias semánticopragmáticas y de sintaxis discursiva entre creo, pienso, opino (verbos propuestos en (1)) e imagino y supongo (incluidos en (2)), si bien en ocasiones se ejemplificará con otros VOP. Se trata, por lo demás, de un trabajo con mirada prospectiva, que pretende abrir puntos de vista con que afrontar el estudio de estos verbos. 
2. Los verbos de opinión entre los verbos “débiles”: contornos sintácticos y semánticopragmáticos

\subsection{Verbos de opinión y subjetividad del lenguaje}

Se habrá reparado en que en (1) y (2) los verbos están en primera persona del singular del presente de indicativo. Existe un generoso número de investigaciones recientes, muchas de ellas publicadas en este siglo, que tienen como objeto describir la semántica -y con ello dar cuenta de los límites de conmutación- y las funciones pragmadiscursivas de la forma performativa de verbos doxásticos en diferentes lenguas, especialmente del francés y del inglés ${ }^{5}$. Es interesante destacar que una gran parte de estos trabajos se apoya en corpus orales conversacionales, y algunos de ellos en discursos orales del lenguaje político, donde se ha visto la rentabilidad retórico-argumentativa de algunos de estos verbos (cf. Simon-Vanderbergen 2000, Fuentes Rodríguez 2010, Fetzer 2014). Citemos, como recientes botones de muestra de esta tupida bibliografía, las contribuciones de Aijmer (1997), Simon-Vanderbergen (2000) y Kaltenböck (2010) sobre I think; o las monografías de Cappelli (2008) y de Mullan (2010) sobre diversos VOP del inglés y del francés. Menos son los estudios centrados en los verbos de opinión del español. Contamos, por ejemplo, con el de De Saeger (2007) para creer y pensar o el de Vázquez Rozas (2006) para supongo; o en Hennemann (2012) se persigue dilucidar si la semántica de creo, pienso y opino es epistémica o evidencial.

El interés por la forma subjetiva de estos verbos se deriva de considerarlos piezas de naturaleza funcional-modal más que léxica. De hecho, para algunos autores los VOP están próximos a los adverbios modales epistémicos (posiblemente, quizás, tal vez, etc.) de tal modo que se los concibe como expresiones, frases, "adverboides" o adverbios epistémicos (Thompson y Mulac 1991: 313; Apothéloz 2003: 249; Comesaña 2004: 651; Vázquez Rozas 2006: 1891). Como prueba de su filiación con los operadores modales, se presenta dicha alternancia en empleos en que los verbos de opinión, al igual que las expresiones modales disjuntas, aparecen en posiciones parentéticas, en posición medial o final, desgajados de la secuencia matriz proposicional, y teniendo como ámbito

\footnotetext{
${ }^{5}$ Hay algunos estudios contrastivos, como el de Mullan (2010) sobre la semántica y las funciones textuales y pragmáticas en la conversación de I think del inglés australiano y de je pense, je crois y je trouve.
} 
de “afectación” de la evaluación modal a toda la cláusula, con la única limitación distribucional de que los VOP no pueden aparecer en el margen izquierdo en posición inicial (6a) ${ }^{6}$. Esto último también los diferencia de otras formas verbales, con diferente grado de lexicalización y gramaticalización, especializadas en la marcación discursiva y que sí pueden ocupar la posición inicial, como oye, mira, vamos, anda, etc. (Martín Zorraquino 2010: 146 y ss.):

(3)Creo que han ganado los europeístas.

(4a) Han ganado, creo, los europeístas.

(4b) Han ganado, probablemente, los europeístas.

(5a) Han ganado los europeístas, creo.

(5b) Han ganado los europeístas, probablemente.

(6a) *Creo, han ganado los europeístas.

(6b) Probablemente han ganado los europeístas.

(6c) Oye, han ganado los europeístas.

La naturaleza modal y el carácter disjunto de los VOP tiene un anclaje de referencia conocido: los trabajos de Benveniste sobre la subjetividad del lenguaje. Este autor manifestó que, entre los hechos existentes en la lengua susceptibles de mostrar al hablante como "sujeto" del discurso, existen dos tipos de verbos que, si aparecen en la modalidad declarativa y si son enunciados en la primera persona del presente de indicativo de la voz activa, tienen un valor semántico particular diferente del resto de las formas de su paradigma (Benveniste 1966: 264-265). Se trata, por una parte, de "verbes de parole", que a partir de Austin se conocerán como verbos performativos; y, por otra, de verbos que denotan “disposiciones u operaciones mentales”, mediante los que el locutor “indica su actitud” sobre el contenido proposicional al que afectan. Según el lingüista francés, no todos los verbos y, en particular, no todos aquellos que significan percepción mental presentan esta asimetría entre la "persona subjetiva” y el resto de formas del paradigma: precisamente, de acuerdo con los ejemplos que proporciona, los verbos en que se da tal asimetría guardan una clara filiación con los VOP (concretamente, ejemplifica con je crois, je présume, je suppose y je conclus). En definitiva, de las palabras de Benveniste se deduce que, en sus enunciaciones subjetivas, ciertos verbos de

\footnotetext{
${ }^{6}$ Cf. los datos que proporciona Vázquez Rozas (2006: 1891) sobre la frecuencia de aparición en construcciones parentéticas de varios de estos VOP en el CREA.
} 
referencia mental tienen un papel informativo secundario, pues funcionan a modo de “(meta)comentario” al margen del contenido de la predicación. Ahora bien, la identidad de "comentario marginal” de estos verbos no solo tiene su reflejo formal icónico en los empleos en que se presentan desgajados constituyendo una unidad entonativa, sino que también funcionan como "indicadores de subjetividad" cuando son regentes de una cláusula completiva.

2.2. Verbos de opinión, verbos parentéticos y verbos de “rección débil”: apuntes de sintaxis discursiva

2.2.1. Este carácter “independiente” quedó célebremente bautizado con la denominación de Urmson (1963), “verbos parentéticos”, marbete que, por cierto, ha estado muy unido a los verbos de opinión (Apothéloz 2003). Ciertamente, no hay que perder de vista que en la clase general de los predicados asertivos se ha intentado mostrar con heterogéneas pruebas sintácticas que el complemento proposicional que introducen "es relativamente independiente de la presencia de éstos, y un reflejo más de su naturaleza parentética” (Bosque 1990: 35), aunque también se ha señalado que, a propósito de algunas de estas pruebas, los predicados asertivos débiles son los más proclives al funcionamiento parentético (Bosque 1990: 27-36; Gachet 2009: 18-21).

Interesante es, a este respecto, traer aquí algunos de estos indicios sintácticos que invitan a reflexionar sobre qué tipo de rección es la que se establece entre el VOP y la cláusula completiva. La más representativa tiene que ver con las dificultades de conmutar la cláusula por un pronombre. En efecto, la imposibilidad de reducir a clítico o incluso a otras proformas tónicas (eso, ça) el contenido clausal ha sido citada a propósito de verbos doxásticos de lenguas como el español, el francés y el inglés (Comesaña 2004; Blanche-Benveniste y Willems 2007: 225; Willems y BlancheBenveniste 2010; Apothéloz 2003: 243-244). Lo revelador es que la imposibilidad de conmutación se produce cuando comparecen integrados en la cadena sintáctica como regentes, y no solo cuando su posible estatuto de operador modal es más "transparente" en sus empleos parentéticos. Esto, naturalmente, los diferencia de muchos otros verbos transitivos. Incluso hay predicados que, en construcciones en inciso final, exigen la presencia del pronombre neutro catafórico (ejemplos de 9): 
(7a)Creo que han ganado los europeístas. $={ }^{*}$ Lo creo. $^{7}$

(7b) Han ganado los europeístas, creo. = Han ganado los europeístas, *lo creo.

(8a)Pienso que han ganado los europeístas. $=*$ Lo pienso.

(8b) Han ganado los europeístas, pienso= Han ganado los europeístas, *lo pienso.

(9a) Juro que vendré mañana $=$ Vendré mañana, lo juro $/ *$ juro.

(9b) Siento que te haya salido mal $=$ Te ha salido mal, lo siento $/ *$ siento.

Lo que vendría a demostrar esta limitación de conmutación pronominal es que en estos casos -(7a) y (8a) - no estamos ante una “rección sintáctica plena”, sino ante una rección de diferente naturaleza que algunos han etiquetado como rección débil (Blanche-Benveniste 1989; Blanche-Benveniste y Willems 2007: 225; Willems y Blanche-Benveniste 2010; Apothéloz 2003), en la que los predicados que pueden ejercer tal tipo de rección, entre los que se han incluido algunos VOP, funcionan, en todo caso, como "seudo-rectores” (Apothéloz 2003: 243). Pues bien, precisamente, la elección del marbete “verbos débiles” obedece a la particular relación que estos verbos tienen con las proformas (Willems y Blanche-Benveniste 2010: 566).

La pronominalización como estrategia de identificación funcional no está exenta de problemas, entre otros motivos porque la conmutación por una proforma clítica de implemento es una estrategia de identificación funcional que tiene sus limitaciones de aplicación (Gutiérrez Ordóñez 1997: 265) ${ }^{8}$. Por lo demás, Gachet (2009: 23-25) plantea sin ambages que esta prueba no tiene suficiente solidez para delimitar la clase de los verbos rectores débiles, pues no es difícil encontrar testimonios de “verbos débiles” con clítico manteniendo su lectura débil, si bien se apresura a afirmar que casos como croire o penser son más delicados, pues "la proximité entre le "sens fort” et le "sens faible” de ces verbes permet difficilement de décider” en cada ocurrencia con clítico cuál es el significado actualizado (Gachet 2009: 23).

Como señala Gachet (2009: 23-24), esta prueba de reducción a clítico de la completiva necesita una serena reflexión, apoyada con corpus, para dilucidar hasta qué punto es rentable para el asunto que ocupa estas páginas. Por lo que respecta al español, en otro lugar apuntamos, con las debidas precauciones, que la pronominalización tiene

\footnotetext{
${ }^{7}$ Cuando los VOP tienen una lectura diferente a la de predicados asertivos débiles no hay problema en la clitización: cf. infra en este mismo epígrafe.

${ }^{8}$ Gachet (2009: 25) se pregunta hasta qué punto las posibilidades y limitaciones de pronominalización se deben a propiedades sintácticas del verbo o a otros factores.
} 
rentabilidad explicativa (González Ruiz 2014: 266-267). En principio, la intuición interpretativa indica que la clitización de la completiva no es posible cuando se actualiza un significado cognitivo doxástico, pero sí se tolera cuando el verbo se emplea con otro significado ${ }^{9}$, pues estos casos el predicado regente pasa a ser la información de primer plano y contrae una relación sintáctica “fuerte” (de subordinación) con la completiva. Esto sucede tanto en los VOP prototípicos (10-12), como en otros que presentan acepciones doxásticas (13-15). Con todo, cabe advertir que de la lectura de los siguientes ejemplos también se intuye que no todos los verbos tienen ambas interpretaciones (fuerte/débil) igualmente “salientes”:

(10) Opino que no se debe hacer así $=$ *Lo opino.

(11a) Creo que Pedro es inocente (admito como verdadero que P) = Lo creo.

(11b) Creo que Pedro es inocente (P es una opinión) $=*$ Lo creo.

(12a) Piensotodas las posibilidades y te informo (examino, reflexiono sobre $\mathrm{P}$ ) $=$ Lo pienso y te informo.

(12b) Pienso que no te conviene ese trabajo (P es una opinión) $=*$ Lo pienso.

(13a) Imaginoque han llegado a casa (represento en mi imaginación P) = Lo imagino.

(13b) Imagino que han llegado a casa (P es una opinión) $=*$ Lo imagino.

(14a) Supongoque han llegado a casa (represento en mi imaginación P) = Lo supongo.

(14b) Supongo que han llegado a casa (P es una opinión) $=$ *Lo supongo.

Existen otras estrategias que también muestran que los VOP presentan una identidad sintáctica y semántico-funcional próxima a los adverbios disjuntos de modalidad. Así, los VOP no toleran otras transformaciones sintácticas que le son vedadas a constituyentes que se ubican en niveles jerárquicos exteriores a la predicación oracional. Por ejemplo, no parece que puedan ser focalizados mediante estructuras sintácticas especializadas en tal función informativa, como las construcciones ecuacionales:

(15a)Creo que han ganado los europeístas, no estoy del todo seguro = lectura débil, opinión.

(15b) Lo quecreo es que han ganado los europeístas = lectura fuerte.

El ejemplo (15b) es gramatical, no cabe duda, pero en él no parece que se mantenga el mismo significado para creo de (11b), ya que el segmento focalizado pasa a ser el foco informativo y esto no es compatible con el mantenimiento de su estatus de operador modalizador. Así pues, en (15b) creo no funciona como modalizador de la proposición completiva sino que describe un estado cognitivo, una creencia (Apothéloz 2003: 243-

\footnotetext{
${ }^{9}$ En el caso de opino no se da tal dualidad, porque siempre aporta contenido doxástico.
} 
244). Precisamente, tenemos aquí ilustrada una oposición muy citada en la bibliografía a propósito del verbo creer y, más concretamente, de los dos significados que puede actualizar su forma performativa, si bien el metalenguaje que los denomina dista mucho de ser unívoco (cf., por ejemplo, para el español, Borrego y otros 1990: 88-89; De Saeger 2007 y Fuentes Rodríguez 2010; Simon-Vanderbergen 2000 para I think): se distingue un creoargumentativo, de creencia o adhesión y otro que se suele tildar como epistémico o de opinión ${ }^{10}$. El primero implica que el sujeto conceptualizador admite como verdadero el contenido proposicional, en cuyo caso su funcionalidad pragmática puede proyectarse hacia el potencial argumentativo del refuerzo de la aserción tal y como se ha visto en algunos géneros discursivos, en particular en el lenguaje político (Fuentes Rodríguez 2010). El segundo se relaciona con la evaluación epistémica débil y con una posible proyección pragmática atenuadora (cf. infra§ 3.1.)

Como apuntan algunos autores (De Saeger 2007; Posio 2013), cabría reflexionar sobre los indicios lingüísticos que actúan como inductores de una u otra lectura -“débil” o “fuerte”- del verbo creo (también de otros VOP): la presencia del pronombre personal sujeto (16a) ${ }^{11}$, la aparición de algunos lexemas, como aquellos vinculados con la verdad o la sinceridad, ya en posiciones periféricas al dictum, ya adjuntos al verbo (17a) o el grado de (im)posibilidad de omisión si el verbo está "en primera persona sin cambio ninguno en el significado del mensaje” (De Saeger 2007: 272). En los siguientes testimonios creo tiene una lectura "fuerte" y, por tanto, admite la clitización de la completiva y puede ser focalizado (16b y $17 \mathrm{~b})$ :

(16a)He leído en varios medios de comunicación que nos suben las pensiones. Yocreo que esto no es verdad, [...]. (El País, 28/12/2011)

(16b) Lo que yo creo es que esto no es verdad.

(17a) Creo sinceramente que cada uno tenemos nuestra responsabilidad en esta crisis[...] (El País, 9/11/2011)

(17b) Lo creo sinceramente.

\footnotetext{
${ }^{10}$ Los términos opinión y creencia (belief/opinion; croyance/opinion) son particularmente ilustrativos respecto de la escasa unanimidad en el metalenguaje empleado. Algunos, como Mullan (2010: 128 y ss.), diferencian la opinión de la expresión epistémica de duda (opinion/belief).

${ }^{11}$ Sobre la expresión u omisión del pronombre sujeto en los VOP y los factores pramadiscursivos que influyen en cada opción, cf. Aijón Oliva y Serrano (2010) y Posio (2013).
} 
Un indicio interesante que han planteado algunos autores es el tipo de acto asertivo de la proposición a la que “afecta” el VOP, como sugiere Gachet (2009: 17) con base en estos ejemplos:

(18a) Je crois qu'il va pleuvoir.

(18b) Je crois qu'il est innocent.

En (18a), un acto asertivo informativo, crois es un verbo débil (avoir l'impression) con una función mitigadora, mientras que en (18b) la completiva da cuenta de un acto asertivo valorativo en el que crois tiene un significado fuerte (avoir la conviction, accorder sa croyance) y, por tanto, a su juicio no es un verbo parentético. Una prueba de ello sería que la completiva de (18b) tolera sin problemas la pronominalización y la de (18a) genera más dudas.

Desde luego, el tipo de acto asertivo favorece una u otra interpretación del VOP. En principio, llevar a cabo un juicio evaluativo (axiológico) implica una suerte de compromiso-responsabilidad del locutor que no es acorde con la lectura débil. Quizá por esto los VOP supongo e imagino son más proclives a afectar a un acto asertivo informativo, pues su propia semántica se vincula a la hipótesis, a plantear un contenido como posible en un mundo de acuerdo con ciertos indicios, mientras que un verbo como opino se orienta más a transmitir juicios de valor personales. En cualquier caso, a mi modo de ver, no debe establecerse una correlación tajante lectura débil-acto informativo-función mitigante, por un lado, y lectura fuerte-acto valorativo-no función mitigadora, por otro. Creo con un acto asertivo valorativo puede orientarse a la lectura débil y, por tanto, a una función pragmática atenuadora y, viceversa, con un acto asertivo informativo puede tener una lectura de creencia o adhesión. Con ejemplos muy transparentes:

(19a) Sí, creo que va a llover, lo creo así sin duda.

(19b) Creo que es inocente, no sé, no estoy seguro, la investigación lo dirá.

La reflexión por medio de estudios de corpus sobre la relevancia de estos y otros indicios lingüísticos para orientar la lectura del VOP “deja abierto un generoso campo, apenas cultivado tanto para el español como para otras lenguas: corroborar si estos indicios funcionan realmente como "orientadores” del significado actualizado por los verbos doxásticos” (González Ruiz 2014: 264). Por otra parte, también ayudarían a refrendar si en verbos cognitivos como creer la forma performativa está orientada a la 
lectura “débil” (Borrego y otros 1990: 88). Ahora bien, repárese en que la doble lectura “débil”/ “fuerte” solo es posible cuando el VOP está en la cláusula regente seguido del complementante que. Sin embargo, el significado propiamente doxástico, aquel que puede proyectarse en una función atenuadora, es el único posible en sus empleos como parentéticos en posición medial o final. En estos empleos disjuntos se han detenido algunos autores para establecer similitudes con los adverbios modales. Por ejemplo, la posibilidad o no de ser afectados por la negación (Schneider 2007: 59,148-150) ${ }^{12}$ :

(20) Ha tenido, *no probablemente, poco tiempo.

(21) Ha tenido, *no imagino/*no pienso, poco tiempo.

Con todo, tropezamos con comportamientos divergentes según las lenguas. Hooper (1975: 107) y otros autores que cita Schneider (2007: 150) han señalado que en inglés, siempre que la proposición afectada por el VOP esté en forma negativa, algunos verbos doxásticos pueden aparecer negados en posición final parentética (ejemplos de 22). En español, los ejemplos de (23) ilustran que únicamente no creo tolera esta construcción (González Ruiz 2014: 256). Ningún otro verbo doxástico, al margen de su semántica y de su grado de gramaticalización, permite esta posibilidad (ejemplos de 24):

(22a) The door isn't closed, I think.

(22b) The door isn't closed, I don't think.

(22c) *The door is closed, I don't think.

(23a) La puerta está cerrada, creo.

(23b) La puerta no está cerrada, no creo.

(23c) *La puerta está cerrada, no creo.

(24a) *La puerta no está cerrada, no pienso/no supongo/no imagino, etc.

(24b) *La película no es tan pesimista, no pienso/no supongo/no imagino, etc.

Por lo demás, algunos autores, al confrontar los adverbios de modalidad y los verbos parentéticos, se fijan en confluencias relativas a empleos autónomos como respuestas a preguntas polares (Schneider 2007: 59). Si se compara la posibilidad de constituir autónomamente enunciado sin términos de polaridad o con ellos ${ }^{13}$, encontramos, efectivamente, concomitancias en el sentido de que creo, supongo o imagino pueden, al

\footnotetext{
${ }^{12}$ Salvo alguna excepción (no sé y sus correlatos en francés e italiano), las expresiones verbales que Schneider (2007) acoge entre las reduced parenthetical clauses no pueden ser negadas.

${ }^{13}$ Cf. González Ruiz (2005: 82) y Martín Zorraquino (1999: 30-31) para el comportamiento de los adverbios epistémicos y de otras clases de adverbios disjuntos modales y enunciativos.
} 
igual que los adverbios modales epistémicos, constituir autónomamente un turno sin término de polaridad positiva. Pero no todos los VOP tienen la misma tolerancia: opino no es posible ni siquiera con término de polaridad; pienso genera dudas de aceptabilidad. Repárese, además, en que tampoco los modalizadores de opinión (en mi opinión, a mi juicio, etc.) pueden ser autónomamente un turno de habla (González Ruiz 2005: 82):

(25) - ¿Ha terminado la película?

- Posiblemente, (sí)/Posiblemente, no.

(26) - ¿Ha terminado la película?

- Creo, (sí)/Supongo, (sí)/Imagino, (sí).

(27) - ¿Ha terminado la película?

- *Opino/?Pienso.

Lo que se ha expuesto en este apartado tiene un alcance que puede medirse acudiendo a estas consideraciones: Martín Zorraquino (1999: 28-29) afirma que las partículas modales (adverbios y locuciones de modalidad, interjecciones) alternan onomasiológicamente con otros procedimientos expresivos, entre los que incluye “verbos realizativos” como no sé, creo yo, opino yo, etc., y añade que estos y otros procedimientos alternativos no son partículas modales porque designan "estados de cosas" o "hechos” y, consecuentemente, sí resisten las pruebas formales de ser negados, cuantificados, coordinados, graduados, etc. Por lo esbozado hasta aquí cabe pensar que algunos VOP presentan comportamientos formales -y semánticopragmáticos- que se ajustan a los que tienen los adverbios disjuntos de modalidad, o, en general, las clases funcionales de las partículas modales.

2.2.2. Reflexionemos un poco más sobre los “verbes recteurs faibles”. Mediante esta denominación Blanche-Benveniste y Willems (2007, 2010) pretenden acoger un inventario de construcciones verbales “atípicas”, que se sitúan en la periferia del dominio verbal, que han recibido atención por su funcionalidad pragmática y que guardan filiación con otras denominaciones que también persiguen bautizar inventarios heterogéneos de formas verbales finitas "parentéticas" y otras construcciones clausales de diversa complejidad estructural: reduced parenthetical clauses (Schneider 2007), comment clauses (Brinton 2008; Kaltenböck 2008), oraciones de comentario (Fuentes Rodríguez 2013b). Seguimos aquí la propuesta de 
Blanche-Benveniste y Willems para pergeñar algunas consideraciones sobre los VOP como verbos “rectores débiles” (cf. también Apothéloz 2003) ${ }^{14}$.

Según Blanche-Benveniste y Willems, los “verbes recteurs faibles” presentan tres realizaciones sintácticas en distribución complementaria: a) la construcción prototípica, aquella en que el verbo aparece en la cláusula matriz como regente de una cláusula completiva; b) empleos como parentéticos o disjuntos, en posición media o final; c) otro tipo de empleos más “autónomos”, etiquetados como “construcciones disjuntas”, en los que constituyen un segmento suprasegmentalmente autónomo (comprendidos, pues, entre pausas) que en secuencias dialógicas se pueden presentar constituyendo turnos de habla en intervenciones reactivas ${ }^{15}$. La verificación de las tres propiedades sintácticas permite "proposer un inventaire limité de verbes qui acceptent à la fois les trois distributions”, verbos entre los que incluyen je pense, je crois, je trouve, j'imagine, j'espère, on dirait o il me semble (Blanche-Benveniste y Willems 2007: 237).

Las tres construcciones sintácticas mencionadas presentan gradaciones de frecuencia y aceptabilidad divergentes en dependencia del VOP de que se trate, lo cual muestra la necesidad tanto de describir cada verbo, como de llevar a cabo estudios contrastivos. Fijémonos aquí solamente en las construcciones en que el VOP tiene una autonomía suprasegmental completa, hasta el punto de constituir aisladamente, en contextos dialógicos, turnos de habla ${ }^{16}$ :

(28) (a) Ha subido la bolsa. Creo/Supongo/Imagino.

(b) Ha subido la bolsa. ??Pienso/*Opino.

(29) (a) No ha subido la bolsa. No creo.

(b) No ha subido la bolsa. *No opino/*No pienso/*No imagino/*No supongo.

\footnotetext{
${ }^{14}$ Cf. González Ruiz (2014: 254-255) para algunas consideraciones sobre los VOP en relación con las reduced parenthetical clauses de Schneider (2007). Cf. Fuentes Rodríguez (2013a y 2013b) para un estado de la cuestión sobre el concepto de comment clause (oraciones de comentario).

${ }^{15}$ Para los VOP del inglés (Thompson y Mulac 1991: 313) se ha señalado otra construcción, propia de la lengua oral, que no se registra ni en español ni en francés actual (Blanche-Benveniste y Willems 2007: 226) y que consiste en la supresión de that: I think exercise is really beneficial. Thompson y Mulac (1991) pretenden defender que la supresión del complementante es un estadio diacrónico previo que permite llegar a los empleos parentéticos y a la reinterpretación del VOP como modalizador epistémico. Cf., no obstante, Vázquez Rozas (2006: 1890-1891) para argumentos diacrónicos que contradicen que los usos parentéticos derivan de esta omisión. Cf. también Aphotéloz (2003: 244).

${ }^{16}$ Cf. González Ruiz (2014: 258-261) para algunas reflexiones sobre los grados de “autonomía” de estos usos "disjuntos" basadas en el sistema de unidades de discurso del grupo Val.Es.Co.
} 
(30) - (No) Ha subido la bolsa / - ¿(No) Ha subido la bolsa?

- Creo/No creo.

- Supongo/Imagino/*No supongo/*No imagino.

- ??Pienso/*No pienso/*Opino/*No opino.

Los ejemplos que se acaban de aducir revelan algunas conclusiones:

a) En general, creo es el VOP que menos restricciones presenta en estos empleos “autónomos”. Los que más restricciones presentan son pienso y opino. Por su parte, imagino y supongo presentan limitaciones si aparecen en forma negativa. Este y otros comportamientos parecen unir a creo, imagino y supongo, frente a opino y pienso, los cuales se vinculan con el contenido ‘mantener una opinión'.

b) Habría que considerar algunas variables que en algunos casos parecen mejorar la aceptabilidad. Por ejemplo, la posposición del pronombre personal hace más natural e incluso permite en el caso de pienso usos autónomos monológicos:

(31) Ha subido la bolsa. Imagino yo/Pienso yo/Sospecho yo.

c) Por lo demás, cabría ver qué ocurre en estos empleos autónomos a propósito de pruebas sintácticas como la pronominalización. En términos generales, se observa el cumplimiento de esta condición formal: o no es posible que el VOP concurra con el clítico neutro o, cuando es factible, el significado ya no es el débil (32). No obstante, nuevamente se intuye que no existe una completa homogeneidad en el comportamiento: considérese en (33) la aceptabilidad -incluso la poca "naturalidad"- de lo supongo con igual lectura que supongo como VOP.

(32) - (No) Ha subido la bolsa/- ¿(No) Ha subido la bolsa?

- Creo=verbo débil/Lo creo=verbo fuerte (tengo la convicción)

- Pienso=verbo débil/Lo pienso=verbo fuerte (lo considero, lo reflexiono)

(33) - (No) Ha subido la bolsa / - ¿(No) Ha subido la bolsa?

- Supongo/Lo supongo/Imagino/??Lo imagino.

En fin, a pesar de lo exiguo de la muestra, se puede colegir que incluso los VOP que más podrían ajustarse al estatus de verbos rectores débiles (creo, supongo, imagino) presentan un comportamiento sintáctico que dista de ser uniforme. En cualquier caso, la propuesta de Blanche-Benveniste y Willems para establecer límites en la clase de los verbos rectores débiles descansa en un valor semántico estable que estas autoras formulan como grado bajo 
de validación del contenido proposicional, que, como se comprobará a continuación, tiene una evidente relación con la descripción semántica que se ha propuesto para los VOP:

Comme si l'énoncé simple véhiculait une assertion trop forte, nos verbes ont pour fonction de l'atténuer en en limitant la validation. Cette validation atténuée implique une forme de 'prise en charge’ par le locuteur (Willems y Blanche-Benveniste 2010).

\section{Modalidad epistémica y evidencialidad en los verbos de opinión}

\subsection{Verbos de opinión y modalidad epistémica}

No cabe duda de que habría que explicar la base semántica que justificara la identificación como clase de los verbos cognitivos de opinión. No disponemos de espacio para desarrollar en profundidad este asunto, pero apuntaremos algunos aspectos que, además de resumir sucintamente lo que se ha venido defendiendo en bibliografía reciente, permiten abrir las puertas necesarias para seguir investigando en la semántica y las funciones pragmadiscursivas de los VOP.

No son pocos los autores que defienden que el semantismo que cohesiona al paradigma de estos verbos es un significado de índole epistémica en el sentido de que mediante estos predicados doxásticos el sujeto experimentador no se compromete con la verdad del contenido proposicional (Comesaña 2002: 253). En este sentido, Haverkate (1994: 123; 1995: 13) considera que mediante los predicados doxásticos los sujetos expresan una creencia (belief), de modo que aquellos no tienen seguridad de que lo descrito en el contenido proposicional se corresponde con la realidad factual. Estas posiciones explican, por un lado, algunas rúbricas con que han sido denominados, como “predicados asertivos débiles” (Hooper 1975) ${ }^{17}$ o "verbos de afirmaciones atenuadas" (Borrego y otros 1990: 83). Y, en segundo lugar, como se deduce también de estas etiquetas, una proyección pragmática que se derivaría de su semantismo es el que se refiere a su empleo con una función pragmática atenuadora en su forma performativa. Incluso, independientemente de cómo se formule el significado común de todos estos verbos, algunos autores como Haverkate llegan a afirmar que los predicados doxásticos

\footnotetext{
${ }^{17}$ Frente a los weak assertive predicates (predicados asertivos débiles), están los predicados de aserción categórica (strong assertive verbs), como saber, insistir, reafirmar, etc. (Hooper 1975).
} 
(creo, pienso, me parece, etc.) se emplean “de un modo paradigmático para producir efectos atenuadores" (Haverkate 1994: 124) ${ }^{18}$.

En la propuesta de Haverkate, en el conjunto de predicados cognitivos, los doxásticos ocupan la zona intermedia en la escala epistémica, entre la subclase de los que este autor denomina epistémicos, que vienen a corresponderse con los predicados de aserción categórica, que expresan seguridad o certeza (saber, ser cierto, conocer, etc.), y la de los dubitativos, que acoge a los de ignorancia e incertidumbre (dudar, ignorar, ser posible, etc.). Ciertamente, la ubicación de los predicados doxásticos en la zona intermedia de esta triple distinción tiene algunos argumentos en que apoyarse. Por un lado, su vinculación con los predicados de duda e incertidumbre descansa en una identidad semántica que se ha venido citando recurrentemente a propósito de los VOP y que podría expresarse en estos términos: "los hablantes que afirman hallarse en un estado doxástico dejan ver que no están seguros de que el contenido de su creencia corresponda a la realidad factual” (Haverkate 1994: 124; cursiva nuestra). Pero, por otro lado, frente a aquellos, los VOP parecen vincularse más a los de conocimiento cierto o seguro si observamos algunos hechos sintácticos. Por ejemplo, frente a los dubitativos, cuya semántica epistémica “induce” a seleccionar el modo subjuntivo, los doxásticos y los de certeza rigen modo indicativo en las subordinadas completivas. Efectivamente, en lo que respecta a la lengua española, existe cierta unanimidad en reconocer que los predicados de opinión, independientemente de la semántica propia de cada uno, en forma afirmativa ${ }^{19}$ seleccionan el indicativo:

(34) Sé que ha llegado a tiempo.

(35) Opino/Pienso/Creo/Supongo/Imagino que ha llegado a tiempo.

(36) Dudo que haya llegado a tiempo.

Como es sabido, la oposición modal indicativo/subjuntivo se ha explicado con base en varios ejes, si bien interrelacionados. El principal tiene que ver con entender que el indicativo se utiliza cuando hay aserción y el segundo cuando no la hay o no es suficientemente independiente (Bosque 1990; Ridruejo 1999: 3219). Esto, naturalmente,

\footnotetext{
${ }^{18}$ Queda para otros trabajos el análisis de estos verbos como tácticas atenuantes. Por lo demás, esta función pragmática ha estado íntimamente vinculada a la noción de verbo parentético. Cf. Fuentes Rodríguez (2013a: § 4) para la vinculación entre hedging y parentéticos.

${ }^{19}$ Cuando son negados se presentan importantes variaciones en las que, por falta de espacio, no vamos a entrar aquí (cf. González Ruiz 2014: § 3.3.).
} 
está relacionado con el peso informativo dado a la cláusula en que comparece cada modo. Con el primero se presenta un hecho asertado introducido como información nueva ausente en el contexto, por tanto con alto peso informativo; con el segundo el contenido de la completiva se presenta como presupuesto, como conocido y, por ello, su peso informativo se desdibuja, pasa a un segundo plano y se realza lo que se transmite en el predicado regente. Pues bien, por lo que respecta a los predicados asertivos débiles del español, la aparición del subjuntivo en sus completivas o genera resultados más o menos inaceptables, o, en aquellos que en su forma afirmativa lo admiten (cf. Borrego y otros 1990: 83-85; Ridruejo 1999: 3222-3228; Haverkate 1995: 17-18), da lugar a una alteración de significado del predicado regente que implica que su interpretación sea diferente a la doxástica. Así pues, en la forma performativa, la aparición del subjuntivo queda bloqueada si el verbo funciona como introductor de una "aserción débil” como se muestra en los ejemplos de (37) a (40). De hecho, Comesaña (2004: 653-655) apunta que una condición para que esta clase de verbos cognitivos tenga el papel de operador modal es que el modo de la completiva esté en indicativo. Y, respecto del verbo creer, señala que "presenta el sentido de pensar, opinar cuando introduce una cláusula completiva en este modo verbal, pero cuando la completiva presenta el modo subjuntivo el verbo pasa a significar aceptar como verdadero, admitir [...]” (Comesaña 2004: 654). Por otra parte, cuando se emplean parentéticamente, no pueden ser inductores de modo subjuntivo, pues su único significado posible es el vinculado a lo doxásticoepistémico (41).

(37a)Creo que ha mejorado.

(37b) Creoque haya mejorado (comprendo, acepto como verdadero).

(38a) Pienso que ha mejorado (creo, opino).

(38b) Pienso que haya mejorado (imagino un marco supuesto).

(39a) Imagino que ha mejorado (creo, supongo).

(39b) Imagino que haya mejorado (lo represento en mi imaginación).

(40a) Estimo que no es una buena película (opino, creo).

(40b) Estimo que hayas venido (aprecio, valoro).

(41a) Ha mejorado, imagino/*Haya mejorado, imagino.

(41b) Su hermano, creo, es un gran contacto/Su hermano, creo, *sea un gran contacto.

Ahora bien, nuevamente tropezamos con que los comportamientos no son homogéneos en las diferentes lenguas. Debe recordarse, afirma Bosque (1990: 36), “que los verbos de aserción débil más característicos, como creer y pensar, se construyen con 
subjuntivo en italiano moderno y también en español antiguo y dialectal, sin que por ello dejen de pertenecer a esa clase semántica”. No obstante, también en este punto cabría ahondar en aspectos como el siguiente: aunque no es del todo anómalo, parece que la forma performativa es más reticente a regir el subjuntivo y, por tanto, a actualizar otro significado diferente al significado cognitivo doxástico. Por ello, pueden causar extrañeza -cabría ver si todos los verbos por igual en todas las variedades diatópicasalgunos de los ejemplos anteriores: (37b), (38b), (39b).

\subsection{Verbos de opinión y evidencialidad}

Un repaso a los trabajos monográficos sobre los verbos doxásticos de varias lenguas en los últimos años muestra, asimismo, el especial florecimiento de propuestas que los consideran "verbos evidenciales”, esto es, marcadores lingüísticos cuyo significado se inscribe en el dominio semántico de la evidencialidad, lo cual conduce a defender que codifican significados relacionados con la fuente o el modo de acceso a la información ${ }^{20}$. Con todo, se sigue planteando que en la semántica de estos verbos hay, además de un contenido evidencial, una semántica epistémica (Cappelli 2008; Hennemann 2012). De hecho, el análisis semasiológico abordado en algunos trabajos sobre las formas performativas de algunos VOP ha llevado a admitir que "it is indeed difficult at first glance to decide whether je pense que/je crois que 'I think' should be considered epistemic modal markers [...] or as evidential markers” (Dendale y Van Bogaert 2007: 67).

No es el objeto de estas páginas profundizar en el "grado" de semántica evidencial que pueda existir en todos o en algunos de los verbos doxásticos ${ }^{21}$, pero sí merece la pena hacer algunas observaciones relacionadas con la evidencialidad, pues, a partir de ellas, es posible corroborar que los VOP “prototípicos” como pienso u opino mantienen un lazo semántico-pragmático estrecho frente a otros como imagino o supongo. Partamos,

\footnotetext{
${ }^{20}$ Varios autores, entre ellos Mullan (2010: 133) y Dendale y Van Bogaert (2007), han caracterizado el trabajo de Ducrot sobre je trouve y otros VOP del francés como una aportación "evidencial” avant la lettre. Uno de los parámetros que Ducrot (1980: 84) maneja para describir la semántica de los verbos objeto de su estudio -entre los que incluye, además de VOP como je crois o je pense, otros como je suis sûr- es el que consiste en dilucidar si el verbo implica o no un juicio basado en una experiencia personal.

${ }^{21}$ Tampoco es este el lugar para entrar en la controversia en torno a la exclusión de los medios léxicos como expresión de la categoría evidencial.
} 
para ello, de las informaciones que proporcionan los diccionarios. En las siguientes definiciones se observa un dato común: de alguna manera está presente la semántica evidencial indirecta, dado que se alude a “indicios”, “señales” o “apariencias” a partir de las que se hace una inferencia o se “construye” una hipótesis:

Sospechar.

1. tr. Aprehender o imaginar algo por conjeturas fundadas en apariencias o visos de verdad. (DRAE)

Sospechar.

Creer en la existencia de cierta cosa o circunstancia por alguna apariencia. (DUE) Imaginar.

2. Presumir, sospechar. (DRAE)

Suponer.

4. tr. Conjeturar, calcular algo a través de los indicios que se poseen. (DRAE)

Varias son las reflexiones que se pueden proponer con base en estas definiciones ${ }^{22}$. Obviamente, no solo la enunciación de estos verbos (supongo, imagino) se erige en el “apoyo” en indicios. También, pongamos por caso, al afirmar Pienso que no ha elegido bien, hay unos indicios que han llevado al locutor a “construir” una opinión. No obstante, parece existir una diferencia fundamental entre pienso, opino, creo “fuerte" por un lado, y supongo e imagino, por otro, cuando son empleados como VOP (más complicado resulta integrar al creo débil en esta oposición), al menos en los casos en que se emplean como regentes de una cláusula completiva.

En términos evidenciales, en ambos casos se comprende que el contenido de la completiva constituye una información a la que no se ha accedido directamente, sino solo indirectamente, a través de unos indicios desde los que el hablante ha efectuado una inferencia determinada. Ahora bien, en el caso de verbos como pienso, opino y creo “fuerte", ese proceso epistemológico queda en un segundo plano: si bien se accedió a esa información por medio de una inferencia, lo relevante es que esa información ha terminado integrándose en el universo de “opiniones” del hablante. En otras palabras, con pienso, opino y el creo de 'adhesión' se pone el acento en el resultado final de un proceso inferencial y no en el propio proceso. En cambio, en el caso de verbos como supongo e imagino, el modo de acceso a la información comunicada es un valor mucho más saliente, ya que estos verbos expresan una

\footnotetext{
${ }^{22}$ Las reflexiones que a continuación se aducen deben mucho a las sugerencias de Dámaso Izquierdo Alegría, a quien agradezco el interés por leer este trabajo.
} 
inferencia supeditada a los indicios de los que se dispone, sin llegar a constituirse como una opinión del hablante y sin que este llegue a mostrar un pleno convencimiento. Las definiciones de estos verbos aportadas dan fe de ello, al hacer referencia constantemente a “indicios”, “apariencias” o “visos de verdad”.

Esta sucinta aproximación puede ser base explicativa de algunos comportamientos semántico-pragmáticos que sirven para diferenciar ambos grupos de VOP:

a) No todos los VOP mantienen los mismos grados de aceptabilidad para concurrir con expresiones de incertidumbre o ignorancia, esto es, con expresiones inscritas en la epistemicidad débil. Supongo o imagino no presentan problema alguno, al igual que creo “débil”(otro comportamiento más que vincula creo con estos dos verbos y que lo diferencia de pienso u opino). Con pienso, opino u otros VOP como considero o estimo, tal concurrencia genera dudas de aceptabilidad. Complementariamente, con expresiones que marcan un grado de epistemicidad alto (estoy seguro, sin duda, etc.) los juicios se dan a la inversa:

(42)Creo/Supongo/Imaginoque eligió bien, no sé, no estoy seguro.

(43) ??Opino/??Considero/??Pienso que eligió bien, no sé, no estoy seguro.

(44) ??Creo/??Supongo/??Imaginoque eligió bien, seguro, sin duda.

(45) Opino/Considero/Pienso que eligió bien, seguro, sin duda.

b) Una segunda consideración de índole evidencial. Supongo o creo -también me parece, pero resulta más dudoso imagino- funcionan bien en inicio absoluto de discurso cuando se efectúa una inferencia "inmediata” basada en un indicio externo. Partamos del mismo contexto que presentan Coltier y Dendale (2004: 52) para oponer algunos modalizadores de opinión del francés:

(46) Imaginons un couple. Chacun est plongé dans sa lecture. L’un ayant perçu un bruit, pourra dire sans qu'aucune interrogation, ni verbale ni gestuelle, n'ait eu lieu:

À mon avis, le chat est sur le paillasson.

??Pour moi/??Selon moi, le chat est sur le paillasson.

En este mismo contexto, se observan estos comportamientos con VOP y modalizadores de opinión del español:

(47) Supongo/?Imagino/Creo/Me parece que el gato está en el felpudo.

(48a) ??Pienso/??Opino/??Considero que el gato está en el felpudo.

(48b) ??En mi opinión, el gato está en el felpudo. 
Estos ejemplos, además de ilustrar que à mon avis no siempre puede ser traducido por en mi opinión, permiten observar que VOP como pienso u opino no funcionan bien en contextos de conjetura o inferencia inmediata.

\section{Final}

El manojo de consideraciones hechas en estas páginas pone sobre la mesa la necesidad de estudios semasiológicos de cada VOP con base en corpus representativos. De este modo, no solo se podrán dilucidar los contornos sintácticos y semántico-pragmáticos de cada ejemplar, sino que también se darán pautas explicativas de las posibilidades y limitaciones de conmutación en las tres construcciones sintácticas (regentes de completiva, parentéticos y empleos autónomos), lo cual, obviamente, redundará en la calidad de posibles estudios contrastivos. Esperamos, al menos, haber pergeñado algunas directrices con que acometer la descripción de esta esfera, que, sin duda, forma parte del amplio campo de "cuestiones abiertas en la lingüística del discurso”.

\section{Bibliografía}

Aijmer, K. (1997): I think, an English modal particle. En: Swan, T. y O. J. Westvik (eds.),Modality in Germanic Languages. Historical and Comparative Perspectives. Berlín/Nueva York: Mouton de Gruyter, 1-47.

Aijón Oliva, M. Á. y M M J. Serrano (2010): El hablante en su discurso: expresión y omisión del sujeto de creo.Oralia 13, 7-38.

Apothéloz, D. (2003): La rection dite “faible”: grammaticalisation ou différentiel de grammaticité?Verbum25 (3), 241-262.

Benveniste, E. (1966): De la subjectivité dans le langage. En: Benveniste, E., Problèmes de linguistique genérale. Vol. I. París: Gallimard, 258-266.

Blanche-Benveniste, C. (1989): Constructions verbales “en incise” et rection faible des verbes. Recherches sur le français parlé 9, 53-73.

Blanche-Benveniste, C. y D. Willems (2007): Un nouveau regard sur les verbes faibles. Bulletin de la Société de Linguistique de Paris102 (1), 217-254. 
Borrego, J. y otros ( $\left.{ }^{4} 1990\right)$ : El subjuntivo. Valores y usos. Madrid: SGEL.

Bosque, I. (1990): Las bases gramaticales de la alternancia modal. Repaso y balance. En:Bosque, I. (ed.), Indicativo y subjuntivo. Madrid: Taurus, 13-65.

Bosque, I. y V. Demonte (eds.) (1999): Gramática descriptiva de la lengua española. Vol. II. Madrid: Espasa-Calpe.

Brinton, L. J. (2008): The Comment Clauses in English. Cambridge: CUP.

Cappelli, G. (2008): “I reckon I know how Leonardo da Vinci must have felt...”. Epistemicity, Evidentiality and English Verbs of Cognitive Attitude. Pari: Pari Publishing.

Coltier, D. y P. Dendale (2004): La modalisation du discours de soi: éléments de description sémantique des expressions pour moi, selon moi et à mon avis. Langue Française 142, 41-57.

Comesaña Iglesias, S. (2002): Los verbos de conocimiento en español.Verba 29, 243-260.

Comesaña Iglesias, S. (2004): Los verbos de opinión como operadores proposicionales. En: Villayandre Llamazares, M. (ed.), Actas del V Congreso de Lingüística General. Vol. I. Madrid: Arco Libros, 649-660.

De Saeger, B. (2007): Evidencialidad y modalidad epistémica en los verbos de actitud proposicional en español. Interlingüística 17, 268-277.

Delbecque, N. y B. Lamirov (1999): La subordinación sustantiva: las subordinadas enunciativas en los complementos verbales. En: Bosque y Demonte (eds.), 1965-2081.

Dendale, P. y J. Van Bogaert (2007): A semantic description of French lexical evidential markers and the classification of evidentials. Rivista di Linguistica19/1, 65-89.

Ducrot, O. (1980): Je trouve que. En: Ducrot, O. y otros, Les mots du discours. París: Minuit, 57-92.

Fetzer, A. (2014): I think, I mean and I believein political discourse. Collocates, functions and distribution.Functions of Language 21/1, 67-94. 
Fuentes Rodríguez, C. (2010): La aserción parlamentaria: de la modalidad al metadiscurso. Oralia 13, 97-125.

Fuentes Rodríguez, C. (2013a): Parentéticos, “hedging” y sintaxis del enunciado. Círculo de Lingüística aplicada a la comunicación 55, < www.ucm.es/info/ circulo/no55/fuentes.pdf > Última consulta: 20-05-2015, 61-94.

Fuentes Rodríguez, C. (2013b):Las oraciones de comentario en español. En: Casanova, E. y C. Calvol (eds.), Actes del 26é Congrés de Lingüística i Filologia Romàniques. Berlín: Mouton de Gruyter, 3708-3719.

Gachet, F. (2009): Les verbes parenthétiques: un statut syntaxique atypique ?Linx 61, 13-29.

González Ruiz, R. (2005): Esa será tu opinión. Aproximación al estudio de las funciones discursivas y sociales de los modalizadores de opinión en español actual. Español Actual 83, 75-98.

González Ruiz, R. (2014): Sintaxis, semántica y discurso: algunas reflexiones en torno a los verbos de opinión (con especial referencia al español). En:Pérez-Salazar, C. e I. Olza (eds.), Del discurso de los medios de comunicación a la lingüística del discurso. Estudios en honor de la profesora María Victoria Romero. Berlín: Frank \& Timme, 245-278.

Gutiérrez Ordóñez, S. (1997): Observaciones sobre el estilo directo en español. En: Gutiérrez Ordóñez, S., Principios de sintaxis funcional. Madrid: Arco Libros, 256-276.

Haverkate, H. (1994): La cortesía verbal. Estudio pragmalingüístico. Madrid: Gredos.

Haverkate, H. (1995): Spanish mood and the expression of cognitive and evaluative meaning. Verba 22, 11-29.

Hennemann, A. (2012): The epistemic and evidential use of Spanish modal adverbs and verbs of cognitive attitude. Folia Linguistica 46 (1), 133-170.

Hooper, J. B. (1975): On assertive predicates. En: Kimball J. (ed.), Syntax and Semantics. Vol. IV. Nueva York: Academic Press, 91-124. 
Kaltenböck, G. (2008): Prosody and function of English comment clauses. Folia Linguistica 42 (1), 83-134.

Kaltenböck, G. (2010): Pragmatic functions of parenthetical I think.En:Kaltenböck, G. y otros (eds.), New Approaches to Hedging. Bingley: Emerald, 243-270.

Martín Zorraquino, Ma A. (1999): Aspectos de la gramática y de la pragmática de las partículas de modalidad en español actual. En: Jiménez Juliá, T. y otros (eds.), Español como lengua extranjera: enfoque comunicativo y gramática. Santiago de Compostela: Universidade, 25-56.

Martín Zorraquino, Ma A. (2010): Los marcadores del discurso y su morfología. En: Loureda, Ó. y E. Acín Villa (eds.), La investigación sobre marcadores del discurso del español, hoy. Madrid: Arco Libros, 93-181.

Moliner, $\mathrm{M}^{\mathrm{a}}$ ( $\left.^{2} 1998\right)$ : Diccionario de uso del español(DUE). Madrid: Gredos.

Mullan, K. (2010): Expressing Opinions in French and Australian English Discourse: a Semantic and Interactional Analysis. Amsterdam/Philadelphia: Benjamins.

Posio, P. (2013): Subject expression in grammaticalizing constructions: The case of creo and acho 'I think' in Spanish and Portuguese. Journal of Pragmatics 63, 5-18.

Real Academia Española ( $\left.{ }^{22} 2001\right)$ : Diccionario de la lengua española(DRAE). Madrid: Espasa.

Ridruejo, E. (1999): Modo y modalidad. El modo en las oraciones sustantivas. En: Bosque y Demonte (eds.), 3209-3251.

Schneider, S. (2007): Reduced Parenthetical Clauses as Mitigators. A Corpus Study of Spoken French, Italian and Spanish. Amsterdam/Philadelphia: Benjamins.

Simon-Vanderbergen, A. M. (2000): The functions of $I$ think in political discourse. International Journal of Applied Linguistic 10, 41-63.

Thompson, S. y A. Mulac (1991): A quantitative perspective on the grammaticizacion of epistemic parentheticals in English. En: Traugott, E. C. y B. Heine (eds.), Approaches to Grammaticalization. Amsterdam/Philadelphia: Benjamins, 313-330. 
Urmson, J. O. (1963): Parenthetical verbs. En: Caton, C. (ed.), Philosophy and Ordinary Language. Urbana: University of Illinois, 220-240.

Vázquez Rozas, V. (2006): Construcción gramatical y valor epistémico: el caso de supongo. En: Villayandre Llamazares, M. (ed.), Actas del XXXV Simposio Internacional de la Sociedad Española de Lingüística. León: Universidad, 18881900.

Willems, D. y C. Blanche-Benveniste (2010): Verbes 'faibles' et verbes à valeur épistémique en français parlé: il me semble, il paraît, j’ai l’impression, on dirait, je dirais. En: Iliescu, M. y otros (eds.), Actes du XXVe Congrès International de Linguistique et de Philologie Romanes. Vol. IV. Innsbruck: Mouton de Gruyter, 565-579.

Recibido: 20 de octubre de 2014 Aceptado: 12 de noviembre de 2014 Revisado: 5 de enero de 2015 Publicado: 22 de junio de 2015 Actualizado: 24 de junio de 2015 